\title{
A group resource-based learning approach
}

James $O$ Jenkin, Department of Life Sciences, University of Hertfordshire

\begin{abstract}
Final year undergraduate students are subject to learning pressures due to the amount, level and variety of reading they are required to undertake in relation to taught sessions and assignments. This paper outlines a group resource-based learning approach designed to facilitate a deeper more critical understanding, while at the same time teaching students the importance of making effective study notes in a time-pressured context.

It is concluded that the teaching approach developed is useful in promoting a more critical understanding, but that final year students still require guidance in the shaping of study notes that summarise key items of knowledge and understanding. Attention is also drawn to the role that the core knowledge and professional values of the Higher Education Academy can play in assessing the validity of a teaching approach.
\end{abstract}

\section{Introduction}

Final year undergraduate students are particularly subject to learning pressures due to the amount, level and variety of reading they are required to undertake in relation to taught sessions and assignments. In the context of the teaching and learning literature, there is great deal of debate about the type and depth of learning that students experience, with this in turn being affected by differing approaches to learning (Gibbs 1992; Ramsden I99I; Biggs 2003). In the final year of undergraduate study, students are generally expected to consult a wider variety of information sources to help them develop a deeper more critical level of understanding than they may have done in previous years of study (QAAHE 2000; UH 2003).

In order to provide a group of final year undergraduate students, undertaking the module 'Environmental Policy and Management' (available to those on the Environmental Management, Environmental Studies and Geography programmes) at the University of Hertfordshire, with a deeper more critical understanding of European Union (EU) water policy, a group resource-based exercise was developed. The teaching approach developed aimed to provide students with an appreciation of the differing types of information they should be consulting, and how important summary notes are when attempting to understand and recall academic knowledge in a time limited and pressured situation.

According to Säljö (1979), a deeper understanding of information occurs when learning involves relating parts of the subject matter to each other and to the real world, and when information obtained is interpreted and understood in a different way. This process can subsequently involve comprehending what is around us by re-interpreting/applying knowledge obtained. By adopting a resource-based learning approach, based upon group working and a variety of differing sources of information, a level of student learning autonomy can be promoted that encourages a deeper understanding of the material provided - if the students are to engage in meaningful conversation they will actively aim to understand the material given to them, which can be verified and discussed in a group situation (Laverty 1998; Biggs 2003). The learning approach developed can also allow greater flexibility in tolerating differing learning styles, which is key to encouraging effective learning amongst an increasingly diverse student body, with students of differing levels of skills and experience working together to achieve a common goal - that of understanding the information presented to them (Beswick 1977; Cox and Gibbs 1994; Laverty 1998). The resource-based learning approach is also useful in promoting a deeper level of understanding, as it more realistically copies how people learn in reality, that is via collection and interpretation of a variety of information to solve problems (Laverty 1998)

This article proceeds to outline and further justify, the teaching method developed, and how the professional and educational validity of the approach was assessed. Finally, the teaching approach developed and implemented is reflected upon, with subsequent modifications being suggested for future use.

\section{Methodology}

In order to facilitate an understanding of EU water policy, by a group of 20 students, the teaching session was broken down into four parts as follows:

\section{Part I (I 0 minutes)}

The students were firstly introduced to the four aims of understanding for the session. They were then requested to split themselves into four groups of five. Part II was then outlined to them.

\section{Part II (50 minutes)}

Prior to the tutorial, four different reading packs were prepared. Each pack contained readings drawn from a variety of sources (i.e. books, journals, magazine, and Internet-based sources). The reading packs were designed to enable a group of students to develop an understanding of a particular area of the chosen topic, which was broken down into four key areas to reflect the four aims of understanding:

i) the development of EU water policy;

ii) the impact of EU water policy in England/Wales;

iii) the impact of EU water policy in a wider European context; and

iv) the future direction of EU water policy.

The group was split into 4 groups of 5 students. Each group was given a different reading pack, with each student being asked to read one of the five readings included. Each student was asked to make brief notes on their reading so that they could then discuss, with their group the reading they had been given. Each group was then required to produce an integrated set of notes reflecting the contents of each reading pack. The integrated notes were to be no more than 2 pages of text. The notes had to be typed, with each member of the group printing off five copies of the notes for each member of the group. These notes would subsequently be needed for Part III of the exercise.

\section{Part III (25 minutes)}

\section{Upon completion of Part II, one member from each of the} original groups was then asked to form a new group. The purpose of rearranging the groups was to create groups that consisted of members who possessed an integrated set of notes derived from each of the reading packs given to the students in Part II. The students were encouraged to discuss with each other the aims of the session in relation to an essay question that was intended to bring together each member's knowledge. The students were required to give each other a copy of their notes from the previous group so as to ensure each member had a complete set of notes relating to the aims of understanding for the session. The question set was entitled 'Critically discuss the development of EU water policy'. 


\section{Part IV (30 minutes)}

Each group was then given 5 minutes to verbally present to the class as a whole how they would have approached the essay question and what in particular they would have discussed. A mock answer, written by myself, was then discussed with the class as a whole to ensure each student understood what was expected from a set perspective. This was also carried out to ensure equality of learning, particularly if one group failed to perform.

\section{Assessing professional and educational validity}

When developing, and/or using, new teaching approaches, it is imperative that the professional and educational validity of such approaches is both assessable and demonstrable. This is central to the maintenance and improvement of teaching standards in higher education. To facilitate this process, the core knowledge and professional values of the Higher Education Academy (HEA) were drawn upon to provide a potential framework for the assessment of the teaching approach detailed in this paper. The core knowledge and professional values of the HEA were chosen, because it is the central organisation in the United Kingdom charged with demonstrating and developing the professional standards of teachers in higher education. Accordingly they provide a widely recognised set of core knowledge and professional values that teachers in higher education must demonstrate if they wish to gain teaching accreditation with the HEA.

To demonstrate the professional and educational validity of the teaching approach developed, linkages with the core knowledge and professional values of the Higher Education Academy were identified, in relation to the areas they list (HEA 2005): in particular, linkages were looked for in relation to the following areas of core knowledge (CELT 2004):

$\mathrm{KI}$ the subject material you will be teaching;

K2 appropriate methods for teaching and learning in the subject area and at the level of the academic programme; models of how students learn, both generically and in their subject;

K4 the use of learning technologies appropriate to the context in which you teach; methods for monitoring and evaluating your own teaching; and

K6 the implications of quality assurance for practice.

Linkages were also looked for in relation to the Higher Education Academy's professional values (HEA 2005):

$\mathrm{VI}$ a commitment to scholarship in teaching, both generally and within your own discipline; respect for individual learners and for their development and empowerment; a commitment to the development of learning communities, including students, teachers and all those engaged in learning support; a commitment to encourage participation in higher education and to equality of educational opportunity; and a commitment to continued reflection and evaluation and consequent improvement of your own practice.

Linkages between each of the core knowledge areas and professional values were identified in the case of the teaching approach developed. The specific details of the linkages identified are detailed in Tables I and 2; on the basis of this information, the learning approach adopted as described here, can be assessed as being professionally and educationally valid.

\section{Table I - Linkages to Higher Education Academy Core Knowledge Values}

KI The activity requires the lecturer to have a good understanding of the both the relevant subject material and also the skills required to write effective and structured notes that aid learning.

K2 The activity would appear to be appropriate for final year students as it assumes a certain level of independent learning skills and maturity in being able to work effectively in time limited situation. It also draws upon the range of material final year students are expected to consult and interpret.

K3 This kind of learning activity is likely to result in deep learning rather than surface learning, as the students are actively engaged in determining the extent of their learning (Gibbs 1992; Ramsden 1991; Biggs 2003).

K4 This activity requires the use of word processing packages wholly appropriate for the level of study, which the students will have become well versed in during the course of their studies.

K5 The session was monitored and evaluated in two key respects: (i) checking that students understood and could apply the material given (this was carried out via the essay question in part iv); and (ii) students were asked for their feedback in relation to how they felt their learning had progressed at the end of the session directly, or to e-mail me if clarification on the material / learning aims was required. This feedback process was carried out to enable improvement of teaching and ensure the session was effective.

K6 Understanding the Benchmark quality standards for your subject, for example in relation to levels of understanding and interpretation of knowledge (QAAHE 2000), plays an important role in being able to demonstrate your knowledge of the implications of quality assurance for practice, and what is expected from students at differing levels of study.

Therefore, the teaching approach outlined in this paper is in itself reflective of an understanding of what quality standards mean for practice. This awareness helps to ensure that checks are put in place to ensure appropriate learning at the correct level. For example, the checking of all the group student notes was key to ensuring that their understanding had reached the expect level. The provision of a mock essay question answer helps to ensure equality and parity of the answer that students are expected to develop in relation to the essay question. The process of assessing knowledge in relation to an essay question also helps to assess understanding. All the integrated student notes were checked for accuracy before being up-loaded to study-net (the University of Hertfordshire's e-learning environment for students). This process was designed to ensure the basic quality of notes produced by students which would be used for future learning/revision purposes. 


\section{Table 2 - Linkages to Higher Education Academy Professional Values}

VI The use and development of this learning approach demonstrates a commitment to scholarship by identifying and developing alternative ways of learning and teaching.

V2 The approach chosen helps to empower the learner via the granting of autonomy during the learning process.

V3 The learning activity encourages the development of learning communities via the active formation of groups. The feedback opportunities also allows the further development of learning communities that are inclusive of students and teachers.

V4 The learning activity encourages equality amongst the student group as it creates a situation whereby students of differing levels of skills and experience work together

V5 The encouragement of student feedback and active follow-up dialogue helps to ensure that the learning activity is continually improved and reflected upon.

\section{Reflections and modifications}

In general, the learning activity progressed well, with the students appearing to engage with the subject material given to them. In Part II, all groups managed to produce an integrated set of notes. However, it was at this stage of the activity that more support than anticipated had to be given in helping the students to structure and focus on what the important aspects of the readings were. Part III and Part IV progressed well, with the students attempting the development of a mock essay answer and entering into discussion with each other. The resultant discussion was monitored, with questions/guidance being given where necessary, particularly if the students were unsure of anything.

At the end of the exercise the students did comment that they would have appreciated a bit more time as they felt too pressurised; and that more guidance in Part II would have been beneficial to allow more independent/directed learning. It was also noted during the exercise that the overseas students had particular difficulty in reading at the required pace and understanding what was expected of them due to language/cultural barriers.

In response to the above outcomes, it is intended that when the teaching exercise is repeated students are:

- Given slightly shorter readings to reduce the associated time pressures;

- Given more guidance in Part II to help them better structure their notes. This will be carried out via the development of series of questions that students must develop answers to. This will help the students to better structure their notes;

- Provided with prior access to the readings to allow those with language/reading difficulties extra time to prepare. However, to maintain the surprise and uniqueness of the teaching approach, the details of the exercise will only be revealed during the teaching session.

\section{Conclusions}

The exercise was successful in teaching students the importance of making effective summary notes when reading, indicating the level and the variety of information they are expected to consult, and the required level of understanding needed to succeed in the final year of undergraduate study. However, the teaching approach revealed the need to ensure that more structured guidance is given on the information that students are expected to identify and understand. Assessment of the developed teaching approach via reference to the core knowledge and professional values of the Higher Education Academy proved useful in helping to offer a method by which the teaching approach developed and implemented could be assessed as being educationally and professionally valid.

\section{Acknowledgements}

The author wishes to thank the Centre for the Enhancement of Learning and Teaching (CELT) at the University of Hertfordshire for faciliating the author's development of this paper as part of the assessment programme for'Understanding and Enhancing Student Learning and Participants' Teaching'. Particular thanks are due to Jenny Blumhof, Indra Jones and William Fisher for their encouragement and patience! In relation to the initial development of the core teaching idea detailed in this paper, the discussions with Anna Cox and Paul Cairns, of UCLIC University College London, are acknowledged and much appreciated.

\section{References}

Beswick, N. 1977. Resource-based learning. Heinemann: London: Biggs, J. 2003. Teaching for Quality Learning at University. OUP: Maidenhead.

Centre for the Enhancement of Learning and Teaching (CELT), 2004. Understanding and Enhancing Student Learning and Participants'Teaching. University of Hertfordshire: Hatfield.

Cox, S, and Gibbs, G. 1994. Course design for resource based learning: Social science. Oxford Centre for Staff Development: Oxford

Gibbs, G. 1992. Improving the Quality of Student Learning. Technical \& Educational Services Ltd: Bristol.

Higher Education Academy (HEA), 2005. Guidelines on the Accreditation of Staff Development Programmes in Teaching and Learning in Higher Education. HEA

Laverty, C. 1998. Resource-based learning. Available at: http://stauffer.queensu.ca/inforef/tutorials/rbl/index.htm. Accessed 19/0I/05. Ramsden, P. 199I. Learning to Teach in Higher Education. Routledge: London

Säljö, R. 1979. Learning in the Learner's Perspective: I: some commonplace misconceptions. Reports from the Institute of Education, University of Gothenburg, 76.

Quality Assurance Agency for Higher Education (QAAHE), 2000. Geography Subject Benchmark Statement. QAAHE: Gloucester.

University of Hertfordshire (UH), 2003. Geography Subject Review Self Evaluation Document. University of Hertfordshire: Hatfield.

James O. Jenkins, Division of Geography and Environmental Sciences , Department of Life Sciences, University of Hertfordshire.

Email: j.o.jenkins@herts.ac.uk 